\title{
Instruction-based selective action pattern (IBSAP): a novel method for talent identification in sports
}

\author{
Sagdilek E. ${ }^{1 \mathrm{ABCDE}}$, Sahin S.K. ${ }^{2 \mathrm{ABCDE}}$ \\ ${ }^{1}$ Faculty of Medicine, Department of Biophysics, Bursa Uludağ University, Turkey \\ ${ }^{2}$ Faculty of Sport Sciences, Department of Coach Training in Sports, Bursa Uludă̆ University, Turkey
}

Authors' Contribution: A - Study design; B - Data collection; C - Statistical analysis; D - Manuscript Preparation; E - Funds Collection.

\begin{abstract}
Purpose:

Talent identification/development programs are utilized by sports federations to select or train elite athletes. In addition to the established tests that assess perceptive and motor skills, it was deemed significant that cognitive skills should be evaluated as well. The present study was undertaken to assess the utility of Instruction-Based Selective Action Pattern (IBSAP), a novel method that we developed, in estimating perceptive, motor as well as cognitive skills of athletes in order for talent identification. We also investigated the relationship between IBSAP and auditory reaction times (ARTs).

Material: $\quad$ Forty-three students (average age: 12.6 years) participated in the study. Random/fixed-interval ARTs were recorded. IBSAP was applied using a table tennis robot that was set up to throw 30 balls in three different colors to different spots on the table with a frequency of $1 \mathrm{ball} / \mathrm{s}$. The subjects were instructed to ignore the white balls, to touch the yellow balls, and to catch the pink balls before the first trial and their scores were calculated in two consecutive trials according to a scoring system.

Results: $\quad$ Our results showed that motor learning, adaptation and reinforcement of the participants were significantly greater in second trial compared with the first trial and that IBSAP values were correlated with ARTs.

Conclusions: $\quad$ We conclude that the IBSAP method reliably provides quantitative data on perception, motor as well as cognitive skills and it can be considered as a useful tool for talent identification.

Keywords: $\quad$ auditory reaction times, cognitive skills, motor skills, perception, table tennis, talent identification.
\end{abstract}

\section{Introduction}

Success in sports, as measured by competitive performance, is dependent upon a number of significant mental and physical components. Age, somatotype, genetic endowment, nutritional status, physiology, psychology, training level, and risk of injury are all major independent variables influencing the performance [1]. Besides the unmodifiable factors, some of which are described above, routine training, motivation and professional guidance since childhood towards a branch of sports are the most significant keys to athletic success [2, 3].

Either individualistic or a team sport, excellent perceptive and motor skills and top level cognitive skills such as intuition and decision making are required in order to achieve the level of an elite athlete in most branches of sports. During a game, an athlete should rapidly adapt to several varying conditions (the opponent, ball, environmental conditions, psychological status, etc.), implement the game plan according to her or his coach, maintain the concentration and mental endurance until the end of the game, and perform the right action at the right time even if fatigue becomes prominent $[4,5]$.

Perceptive, cognitive and motor skills coexist in different proportions in all branches of sports [6-8]. However, in sports branches where time is minimized to reflexes and perceptive and motor abilities reach maximum limits, mental and cognitive components become the significant determinant for the differences between athletes [9-11].

\footnotetext{
(c) Sagdilek E., Sahin S.K., 2019

doi:10.15561/18189172.2019.0506
}

Athletic achievement in Olympics and international competitions is an important sign of strength. Financial revenue created by sports resembles a market where more is desired everyday by clubs, sponsors and the athletes. Thus, it is of utmost importance for national athletic federations and sports clubs to select athletes with a potential for success in future. Today, many national federations select young athletes via talent identification / development programs and follow up their progress [1214]. Most of the skill tests used in these talent identification and development programs assess perceptive and motor skills [15-17]. However, due to the fact that mental and cognitive skills play a more significant part in athletic achievement, tests that assess cognitive skills in particular has attracted significant attention recently [18-20]. Most cognitive tests are applied either desk-bound or as simulation tests and are far from the ecologic nature of sports $[21,22]$. In addition, it is suggested that all skills (perceptive, motor and cognitive) must be evaluated by tests that mimic all components of performance in sports $[23,24]$. However, to the best of our knowledge, no method that evaluates cognitive skills along with perception and motor skills in a single test has been published yet in the literature.

In a recent manuscript reviewing the test methods used for talent identification among young racket athletes, Faber et al [24] reported that more than 100 tools which focused on intellectual and perceptive skills were used in these tests, and that coordinative skills were determinative in identifying the future elite athletes. In accordance, the hand-eye coordination test that the authors developed was 
demonstrated to be a valid test for table tennis athletes [25].

We developed, in our previous studies, a method that we had named "Selective Action Array" in order to reveal the diversities in table tennis. The Selective Action Array is a useful tool for obtaining basic information on perceptive, cognitive and motor skills as well as associating such cognitive skills as attention, maintenance of concentration, learning and reinforcement with motor skills in a quantitative manner. This method allowed us to compare the differences in skill levels of table tennis athletes with non-athletes [26] or with advanced computer game players [27], and make comparisons between genders in table tennis athletes [28].

In the present study, we investigated whether our method could be utilized for talent identification in sports. In addition, we evaluated the relationship between our method and the auditory reaction time, which is an indicator of perception and motoric outcome, and generally regarded as a useful parameter for talent identification. In an attempt to express the content and purpose of the study more clearly, we have revised the name of this method as "Instruction-Based Selective Action Pattern" (IBSAP) since this expression is more accurate due to the fact that the participants are given solid instructions and their action patterns are quantified before and after the test, respectively.

\section{Material and Methods}

The study was conducted at Faculty of Sports Sciences at Uludag University, Bursa, Turkey, during February and March, 2014. Ethical approval was obtained from Uludag University Ethics Committee on Clinical Research.

Participants
Participants included a total of 43 students ( 27 females and 16 males) at a mean age of $12.6 \pm 0.8$ (range 11-14) years with middle and low socio-economic status from peripheral villages of Bursa province who practiced beginner level taekwondo. They participated in this study during the $2^{\text {nd }}$ and $3^{\text {rd }}$ weeks of taekwondo training between 10:00 - 12:00 hours. Signed informed consents were provided by themselves and their parents before the study onset.

The students were inquired about demographic and general health information, engagement in sports, and their dominant hands. They did not suffer any acute or chronic disease and nor had visual/auditory impairment either at the time of inclusion or on the day of test procedure. We determined that none of the female students was previously trained in a sports discipline under supervision of a coach while only two male students were officially trained by a coach in a summer camp or course (football and taekwondo).

Measurements of height, weight, and whole body impedance (WBI) were performed for all participants using Tanita BC- $418^{\circledR}$ (TANITA Corporation, Tokyo, Japan) device. Later on, subjects' auditory reaction times (ARTs) were recorded using BioPac MP36 ${ }^{\circledR}$ (BIOPAC Systems, Inc., CA, USA) system. On performing the ART, the device was set up to perform a click sound with random intervals (RIs) in the initial 10 trials and with fixed intervals (FIs) in the following 10 trials. The subjects were asked to push a button using their dominant hands when they heard the click sound in their headphones. Mean values (expressed as milliseconds; ms) for each 10 trials were determined as RI-ART and FI-ART.

Instruction-Based Selective Action Pattern (IBSAP)

IBSAP was applied with a table tennis robot (Butterfly/

Table 1. Scoring system.

\begin{tabular}{ll}
\hline $\begin{array}{l}\text { Athlete's Reaction to each White Ball (initially instructed to ignore the white } \\
\text { balls) }\end{array}$ & Points earned at each white ball \\
\hline Ignored & 6 \\
Reacted but did not touch & 4 \\
Touched & 2 \\
Caught & $\mathbf{0}$ \\
Athlete's Reaction to each Yellow Ball & Points earned at each yellow \\
(initially instructed to touch the yellow balls) & ball \\
Touched & 6 \\
Reacted but could not touch & 4 \\
Caught & 2 \\
Ignored & $\mathbf{0}$ \\
Athlete's Reaction to each Pink Ball & Points earned at each pink ball \\
(initially instructed to catch the pink balls) & 6 \\
Caught & 4 \\
Reacted but could not catch & 2 \\
Reacted but could not touch & 0 \\
lgnored & \\
\hline
\end{tabular}


Amicus-3000) [Tamasu Butterfly Europa GmbH, Düsseldorf, Germany]). The robot was programmed to throw a total of 30 balls in three different colors (white, yellow and pink; 10 balls each) randomly at the same speed at a frequency of 1 ball per second that were directed to different spots on the table. The subjects were clearly instructed to ignore the white balls, touch the yellow balls, and catch the pink balls using their dominant hands after the ball bounced once on the table, but were not given a chance to observe the procedure. The instructed responses to the white, yellow and pink balls were considered to serve to the purpose of performing a minimum, moderate and maximum difficulty level, respectively. Responses of the participants to each colored ball were transferred into points on a scale of 0 to 6 (Table 1). Six points referred to ignoring the white ball, touching the yellow ball and catching the pink ball. The sum of color points for each colored ball was expressed as "color score"; the sum of color scores for all balls was expressed as "total score" and the percentage of 6-point responses of the participant to each colored ball was expressed as "\% 6-point response". Two consecutive trials were conducted with a very short interval (approximately 1-2 min) covering the time spent for setting up the robot for the second trial. All trials were recorded on video camera.

Statistical Analysis

Results are presented as mean, standard deviation, and minimum and maximum values. In-group dependent variables were compared using paired t-test and Wilcoxon rank sum test for normally and abnormally distributed variables, respectively. Between-group comparisons were conducted with t-test and Mann-Whitney U-test for normally and abnormally distributed variables, respectively. Spearman test was used for correlation between reaction times, as well as for correlation between reaction times and IBSAP parameters. Significance level was set at $\mathrm{p}<0.05$.

\section{Results}

Descriptive statistics and measurements of height, weight, body mass index (BMI), body fat percentage and fat content as well as WBI of participants obtained by using Tanita BC-418 device have been presented in Table 2. We found no significant difference in terms of age, height, weight, BMI and fat content between female and male participants, while body fat percentage and WBI of the females were significantly $(p<0.05)$ higher than those of the males (Table 2).

Table 3 demonstrates RI-ART and FI-ART values for all participants as well as for females or males separately. Although the males were faster for an average of $25 \mathrm{~ms}$ $(10 \%)$ in both RI-ART and FI-ART than females, the difference was not statistically significant (Table 3). On the other hand, FI-ART was significantly shorter for 45 ms than RI-ART, for all participants $(\mathrm{p}<0.001)$ as well as when females $(p<0.001)$ and males $(p<0.01)$ were considered separately (Table 3 ). These findings suggest that predictable auditory input decreases the reaction time of participants by about $16 \%$, and this effect is independent of the gender.

IBSAP Results

Color scores, total scores and \% 6-point response values obtained in $1^{\text {st }}$ and $2^{\text {nd }}$ trials in IBSAP are presented in Tables 4 and 5 . Our results showed that color scores and \% 6-point response values for each colored ball (Table 4) as well as total scores for all balls (Table 5) were

Table 2. Age, height, weight, body mass index (BMI), body fat percentage and fat content, and whole body impedance (WBI) of subjects.

\begin{tabular}{|c|c|c|c|c|}
\hline Descriptive & Total $(n=43)$ & Female $(n=27)$ & Male $(n=16)$ & $\mathbf{p}$ \\
\hline Age (year) & $12.6 \pm 0.8(11-14)$ & $12.5 \pm 0.8(11-14)$ & $12.8 \pm 0.7(12-14)$ & $p>0.05$ \\
\hline Height $(\mathrm{cm})$ & $153.0 \pm 6.7(133-165)$ & $153.0 \pm 5.7(142-163)$ & $152.0 \pm 8.3(133-165)$ & $p>0.05$ \\
\hline Weight (kg) & $43.9 \pm 9.3(23.8-65.8)$ & $42.8 \pm 7.7(27.0-60.5)$ & $45.9 \pm 11.5(23.8-65.8)$ & $p>0.05$ \\
\hline BMI $\left(\mathrm{kg} / \mathrm{m}^{2}\right)$ & $18.7 \pm 3.1(12.0-27.2)$ & $18.2 \pm 2.6(12.0-23.6)$ & $19.6 \pm 3.8(13.5-27.2)$ & $p>0.05$ \\
\hline Body Fat\% & $20.2 \pm 5.3(12.1-31.9)$ & $21.6 \pm 4.1(12.4-31.3)$ & $17.9 \pm 6.3(12.1-31.9)$ & $p<0.05$ \\
\hline Fat $(\mathrm{kg})$ & $9.2 \pm 3.9(3.2-19.3)$ & $9.5 \pm 3.3(3.4-18.9)$ & $8.6 \pm 4.8(3.2-19.3)$ & $p>0.05$ \\
\hline WBI (ohm) & $694.0 \pm 95.3(514-953)$ & $721.4 \pm 59.4(630-851)$ & $648.5 \pm 125.5(514-953)$ & $p<0.05$ \\
\hline
\end{tabular}

Table 3. Comparison of random interval auditory reaction times (RI-ARTs) and fixed interval auditory reaction times (RI-ARTs).

\begin{tabular}{llll}
\hline Participants & RI-ARTs $(\mathbf{m s})$ & FI-ARTs $(\mathbf{m s})$ & $\mathbf{p}$ \\
\hline Total $(\mathrm{n}=43)$ & $285.3 \pm 58.9(206-551)$ & $240.0 \pm 54.8(173-437)$ & $\mathbf{p}<0.001$ \\
Female $(\mathrm{n}=27)$ & $294.0 \pm 63.2(222-551)$ & $249.4 \pm 58.6(191-437)$ & $\mathbf{p}<0.001$ \\
Male $(\mathrm{n}=16)$ & $270.6 \pm 49.1(206-370)$ & $224.2 \pm 45.1(173-310)$ & $\mathbf{p}<0.01$ \\
$\mathbf{p}$ & $\mathrm{p}>0.05^{\mathrm{a}}$ & $\mathrm{p}>0.05^{\mathrm{a}}$ & \\
\hline
\end{tabular}

${ }^{a}$ : Female versus male 
significantly higher in the second trial than those in the first trial. In addition, color scores and \% 6-point response values of participants differed significantly between colored balls (i.e., the highest scores and success rates were obtained with responses to white balls and the lowest scores and success rates were obtained with responses to pink balls) in both the first and the second trials (Table 4). These findings suggest that the significantly greater scores obtained in the second trial are associated with adaptation of the participants to the test procedure and motor learning. Moreover, the difference in color scores and \% 6-point response values between colored balls confirmed the gradual difficulty level of the IBSAP.

Comparisons of the data obtained by the IBSAP with regard to gender are presented in Table 6. No difference was detected in color scores and \% 6-point response values for the white ball between the genders in either the first or the second trial. A significant difference between genders (i.e., males scored greater) for the yellow ball was detected in the first, but not the second trial, while males scored greater in both trials with the pink ball. Total scores of the males in the first trial were significantly higher than those of the females while the difference was not significant in the second trials. These findings show that there is a significant gender difference in favor of males in association with the difficulty level of the IBSAP test and suggest that this difference may derive from adaptation and motor learning capabilities as well as the readiness levels of males.

In an attempt to investigate the relationship between RI-ART and FI-ART, we found a positive correlation demonstrated by the finding that participants who had shorter RI-ARTs, had also shorter FI-ARTs $(p<0.001$, $\mathrm{r}=0.786$ ) (Table 7). No relation was found between FIART and color scores, total scores and \% 6-point response values. On the other hand, there was a significant negative correlation between RI-ART and the responses of the participants to the yellow and pink balls in the first, but not second trials. This finding shows that participants with shorter RI-ARTs scored higher during first trials with moderate and maximum difficulty levels confirming that randomness in the sound stimulus and the randomness in ball throwing overlapped. In contrast, the correlation between RI-ART and participants' responses was compromised in the second trial which is probably due to motor learning.

Table 4. Results obtained in first and second trials for each colored ball in IBSAP.

\begin{tabular}{|c|c|c|c|c|c|c|}
\hline \multirow{2}{*}{ IBSAP Parameters } & \multicolumn{2}{|c|}{ WHITE $(n=43)$} & \multicolumn{2}{|c|}{ YELLOW (n=43) } & \multicolumn{2}{|l|}{ PINK (n=43) } \\
\hline & First Trial & Second Trial & First Trial & Second Trial & First Trial & Second Trial \\
\hline $\begin{array}{l}\text { Color score } \\
\text { (max: } 60 \text { points) }\end{array}$ & $\begin{array}{l}54.2 \pm 5.6 \\
(28-60)\end{array}$ & $\begin{array}{l}56.8 \pm 5.1^{a} \\
(28-60)\end{array}$ & $\begin{array}{l}46.2 \pm 9.6^{b} \\
(19.1-60)\end{array}$ & $\begin{array}{l}52.4 \pm 6.9^{a, d} \\
(30.4-60)\end{array}$ & $\begin{array}{l}34.8 \pm 11.2^{b, c} \\
(11.4-55.7)\end{array}$ & $\begin{array}{l}43.1 \pm 9.7^{a, d, e} \\
(16.8-57.3)\end{array}$ \\
\hline \% 6-point response & $\begin{array}{l}79.4 \pm 16.5 \\
(16-100)\end{array}$ & $\begin{array}{l}89.7 \pm 14.0^{a} \\
(20-100)\end{array}$ & $\begin{array}{l}61.6 \pm 21.9^{b} \\
(18.8-100)\end{array}$ & $\begin{array}{l}77.5 \pm 18.4^{a, d} \\
(35-100)\end{array}$ & $\begin{array}{l}22.3 \pm 23.6^{b, c} \\
(0-78.6)\end{array}$ & $\begin{array}{l}37.3 \pm 25.6^{a, d, e} \\
(0-89.5)\end{array}$ \\
\hline $\begin{array}{l}\mathrm{n} \text { of participants } \\
\text { with 6-point } \\
\text { response to all balls } \\
\text { in each color } \\
\mathrm{n} \text { of participants }\end{array}$ & 2 & 11 & 1 & 5 & 0 & 0 \\
\hline $\begin{array}{l}\text { with no 6-point } \\
\text { response to all balls } \\
\text { in each color }\end{array}$ & 0 & 0 & 0 & 0 & 12 & 4 \\
\hline
\end{tabular}

a, Compared with first trial values within same colored ball; $p<0.001$

b, Compared with first trial values of the white ball; $p<0.001$

c, Compared with first trial values of the yellow ball; $p<0.001$

${ }^{d}$, Compared with second trial values of the white ball; $p<0.001$

e, Compared with second trial values of the yellow ball; $p<0.001$

Table 5. Results obtained in IBSAP with all balls in first and second trials.

\begin{tabular}{llll}
\hline IBSAP Parameters & First Trial $(\mathbf{n}=\mathbf{4 3})$ & Second Trial $(\mathbf{n}=\mathbf{4 3})$ & $\mathbf{p}$ \\
\hline Total score & $135.3 \pm 19.3$ & $152.4 \pm 16.1(118.8-176.3)$ & $\mathbf{p}<0.001$ \\
(max: 180 points) & $(90.5-167.9)$ & & \\
n of participants receiving $<100$ points & 2 & 0 & \\
$\mathbf{n}$ of participants receiving $>\mathbf{1 6 0}$ points & 5 & 16 & \\
\hline
\end{tabular}


Table 6. Comparison of gender with regard to data obtained in IBSAP.

\begin{tabular}{|c|c|c|c|c|}
\hline \multicolumn{2}{|c|}{ Color score } & \multirow{2}{*}{$\begin{array}{l}\text { Female }(n=27) \\
54.3 \pm 4.3(40-58.9)\end{array}$} & \multirow{2}{*}{$\begin{array}{l}\text { Male }(n=16) \\
54.0 \pm 7.5(28-60)\end{array}$} & \multirow{2}{*}{$\frac{p}{p>0.05}$} \\
\hline Whito & First Trial & & & \\
\hline VVIIILE & Second Trial & $57.1 \pm 2.9(49.5-60)$ & $56.4 \pm 7.7(28.4-60)$ & $p>0.05$ \\
\hline \multirow{2}{*}{ Yellow } & First Trial & $44.5 \pm 8.5(19.1-56.3)$ & $49.1 \pm 10.9(20-60)$ & $p<0.05$ \\
\hline & Second Trial & $51.9 \pm 6.2(37.7-60)$ & $53.3 \pm 8.0(30.4-60)$ & $p>0.05$ \\
\hline \multirow{2}{*}{ Pink } & First Trial & $30.9 \pm 9.1(11.4-50.4)$ & $41.4 \pm 11.7(12.5-55.7)$ & $p<0.01$ \\
\hline & Second Trial & $40.4 \pm 8.6(16.8-54.7)$ & $47.8 \pm 9.9(22.2-57.3)$ & $p<0.01$ \\
\hline \multicolumn{5}{|c|}{ Total score } \\
\hline & First Trial & $129.8 \pm 17.8(90.5-163.1)$ & $144.6 \pm 18.5$ (101.4-167.9) & $p<0.05$ \\
\hline & Second Trial & $149.4 \pm 14.4(118.8-174.7)$ & $157.4 \pm 18.0(121.2-176.3)$ & $p>0.05$ \\
\hline \multicolumn{5}{|c|}{ \% 6-point responses } \\
\hline \multirow{2}{*}{ White } & First Trial & $79.0 \pm 13.8(47.4-95.7)$ & $80.2 \pm 20.8(16-100)$ & $p>0.05$ \\
\hline & Second Trial & $89.7 \pm 10.0(63.6-100)$ & $89.6 \pm 19.4(20-100)$ & $p>0.05$ \\
\hline \multirow{2}{*}{ Yellow } & First Trial & $53.6 \pm 18.6(18.8-86.4)$ & $75.0 \pm 20.9(25-100)$ & $p<0.01$ \\
\hline & Second Trial & $74.0 \pm 19.2(35-100)$ & $83.3 \pm 15.8(47.8-100)$ & $p>0.05$ \\
\hline \multirow{2}{*}{ Pink } & First Trial & $10.9 \pm 17.1(0-60)$ & $41.6 \pm 20.7$ (3.4-78.6) & $p<0.001$ \\
\hline & Second Trial & $25.6 \pm 19.5(0-73.3)$ & $57.1 \pm 22.6(12.5-89.5)$ & $p<0.001$ \\
\hline
\end{tabular}

Table 7. Relationships between random interval auditory reaction times (RI-ARTs), fixed interval auditory reaction times (FI-ARTs), and IBSAP values.

\begin{tabular}{|c|c|c|c|}
\hline \multicolumn{2}{|c|}{$\begin{array}{l}\text { Reaction times } \\
\text { IBSAP Parameters }\end{array}$} & RI-ARTs & FI-ARTs \\
\hline \multicolumn{2}{|c|}{ RI-ARTs } & & $p<0.001 \quad r=0.786$ \\
\hline \multicolumn{2}{|l|}{ FI-ARTs } & $p<0.001 \quad r=0.786$ & \\
\hline \multicolumn{4}{|c|}{ IBSAP Color score } \\
\hline \multirow{2}{*}{ White } & First Trial & $p>0.05$ & $p>0.05$ \\
\hline & Second Trial & $p>0.05$ & $p>0.05$ \\
\hline \multirow{2}{*}{ Yellow } & First Trial & $p<0.01 \quad r=-0.408$ & $p>0.05$ \\
\hline & Second Trial & $p>0.05$ & $p>0.05$ \\
\hline \multirow{2}{*}{ Pink } & First Trial & $p<0.05 \quad r=-0.332$ & $p>0.05$ \\
\hline & Second Trial & $p>0.05$ & $p>0.05$ \\
\hline \multicolumn{4}{|c|}{ IBSAP Total score } \\
\hline & First Trial & $p<0.05 \quad r=-0.317$ & $p>0.05$ \\
\hline & Second Trial & $p>0.05$ & $p>0.05$ \\
\hline \multicolumn{4}{|c|}{ IBSAP \% 6-point responses } \\
\hline \multirow{2}{*}{ White } & First Trial & $p>0.05$ & $p>0.05$ \\
\hline & Second Trial & $p>0.05$ & $p>0.05$ \\
\hline \multirow{2}{*}{ Yellow } & First Trial & $p<0.01 \quad r=-0.409$ & $p>0.05$ \\
\hline & Second Trial & $p>0.05$ & $p>0.05$ \\
\hline \multirow{2}{*}{ Pink } & First Trial & $p<0.05 \quad r=-0.323$ & $p>0.05$ \\
\hline & Second Trial & $p>0.05$ & $p>0.05$ \\
\hline
\end{tabular}

\section{Discussion}

In the present study, we describe the utility of a novel method, Instruction-Based Selective Action Pattern (IBSAP), in talent identification and its relation with auditory reaction time. This method has the potential to provide a collective idea about perceptual, motor and cognitive skills. It was structured by a total of 30 balls in 3 different colors thrown at a frequency of 1 ball per second on different spots of a table by a table tennis robot. The participants were instructed to perform 3 different actions with gradually increasing difficulty levels based on the color of the balls immediately before the test. The 
method was performed in two consecutive trials which provided the ability to correlate cognitive concepts such as adaptation, motor learning and reinforcement with motor skill. In addition, visual perception/attention, continuity of concentration and motor coordination were assessed by testing different skill levels such as catching and releasing some of the balls (pink), touching some others (yellow), and ignoring the rest (white).

The reason for developing the IBSAP with two consecutive trials is that the method governs the potential to evaluate cognitive performances of the participants in addition to motor skills. In the first trial, the subjects attempted to perform the actions that they were instructed, but never witnessed before. In the second trial however, the participants were already experienced and the success rate was higher due to motor learning, reinforcement and adaptation (to the environment, the ball, bounce of the ball, and catching it using their hands). Therefore, it could be suggested that participants who scored higher in the first trial had a higher level of readiness, and those who had greater differences between their first and second trials experienced better learning and adaptation processes.

The fundamental logic of the IBSAP comes from the fact that a separate action was assigned to balls in different colors. Significant differences in color scores and \% 6-point response values in each colored ball indicate the successful designation of gradually increasing difficulty levels in this method. In accordance, we found that scores of participants in their second trials with higher difficulty level (pink vs. yellow/white and yellow vs. white) were not achieved in their first trial with lower difficulty level (white vs. yellow/pink and yellow vs. pink) (Table 4).

We also investigated gender difference in the present study. Males scored higher in both trials at maximum difficulty level (pink balls), in only the first trial at moderate difficulty level (yellow balls) but no difference was detected between males and females at minimum difficulty level (white balls) in two trials. The difference between the genders at moderate difficulty level was not detected in the second trial due, probably, to motor learning achieved by females, while at the maximum difficulty level, even motor learning was not adequate to catch up with the males' scores. These findings suggest that the degree of difficulty among different colored balls were set up appropriately in this method and performing the test by two consecutive trials reveals positive consequences. Higher motor readiness level of males was demonstrated by the IBSAP.

The positive correlation between RI-ART and FI-ART that we showed in the present study is in good accord with previous reports $[29,30]$. In addition, that FI-ART had no relationship with IBSAP parameters as shown in our study could be expected since the constant pattern of the FI-ART measurement and the internal complexity of IBSAP are two irrelevant conditions. The relationship between RI-ART and IBSAP parameters, however, is rather interesting. As demonstrated in Table 7, no relation exists between RI-ART and responses of the participants at minimum difficulty level while RI-ART is negatively correlated with participants' responses at first, but not second, trials of moderate and maximum difficulty levels. These findings show that the randomness in the time of arrival of the balls and randomness of the auditory stimuli coincide during first trial and with learning at second trial, this relationship disappears. Therefore, the relationship between RI-ART and moderate to maximum difficulty levels at first trials suggests that the IBSAP could be an efficient talent identification method.

A number of previous studies reported the significance of assessing eye-hand coordination in table tennis [25, 31]. Faber and colleagues developed an eye-hand coordination test on children at 7-12 years of age in which children needed to throw a ball against a vertical positioned table tennis table with one hand and to catch the ball correctly with the other hand as frequently as possible in 30 seconds [25]. Four different test versions were assessed varying the distance to the table ( 1 or 2 meter) and using a tennis or table tennis ball in this test. The authors showed that the best version for talent identification was the one which was performed by catching the table tennis ball from 1 meter and suggested that the eye-hand coordination test that they developed could be used as a skill selection test. Although the test developed by Faber and colleagues [25] is compatible with the ecological nature of table tennis, it only provides assessment for perceptiomotor skills, while cognitive skills cannot be evaluated. However, our IBSAP method enables assessment of perceptual selectivity, different motor skill levels as well as cognitive skills. In addition, the eye-hand coordination test includes a time constraint while IBSAP does not. Therefore, the process that continues until scoring a point in racquet sports can be considered to be well-reflected in the IBSAP.

In a study by Toriola and colleagues [32], the relation of initial ball-balancing and -bouncing skills of beginnerlevel table tennis players with their achievements in a table tennis tournament after a period of training was investigated. Interestingly, the authors reported a negative correlation between initial ball control skill scores of the participants and their rankings at end of the table tennis tournament. Therefore, assessing solely the motor skills by coordination tests may not represent an optimum method and additional procedures testing cognitive skills should be considered for a multidimensional evaluation of talent identification.

Reaction time and inhibitory control as a function of cognition were investigated using a novel method which was tested on badminton athletes [33]. However, in this test cognitive skills were investigated in association with a single motor movement while in our method cognitive skills were associated with motor skills at three graduallyincreasing levels of difficulty.

The primary limitation of the present study is the lack of reliability and validity studies on the method. The student group that we included in the study was discharged from their training unexpectedly, thus preventing us to conduct the planned further tests.

However, the primary objective of the present study was to evaluate quantitatively motor and cognitive skills of 
participants initially and measure their relations with data obtained in the second trial using the same experimental set up. Therefore, in brief, the purpose of the method is to find the measure of how quickly a person can adapt to a situation that is encountered for the first time. The difference in points between the two trials is indicative of this adaptation. In racquet sports particularly, playing 3 to 7 sets and winning 2 to 4 of them is associated not only with motor skills but also with adaptation and learning processes and the player's chance of winning the game is higher with adaptation to opponent's style, in cases where motor skills are similar.

\section{Conclusion}

In conclusion, the method that we developed and presented in this report allows assessment of an individual's (i) visual attention/perception, (ii) cognitive skills/functions such as, motor learning ability, adaptation and reinforcement, and (iii) motor readiness levels. Therefore, in today's world where assessment of cognitive components has become significant in athlete selection, our method may provide a useful tool for predicting cognitive skills in addition to perceptual and motor skills particularly in racquet sports like table tennis due to its ecological nature both in terms of method and game process. In order to test whether our method could predict an elite athlete, it would be interesting to follow-up the best scorers in the present study for whether they would succeed in a sports branch in the future. In addition, the method could be modified in several aspects to evaluate performances of elite athletes. Hence longer-term studies, perhaps including various modifications, are warranted for this purpose.

\section{Acknowledgements}

This study was initially presented in $26^{\text {th }}$ National Biophysics Conference (September 9 - 12, 2014. Gaziosmanpaşa University, Tokat, Turkey).

This work was supported by the Uludağ University Scientific Research Projects Agency under Grant [KUAP(E) - 2013/57].

We would like to express our gratitude to Sports Sciences Faculty, Physical Education Teaching Department students Hazni Akın, Beyhan Aksu, Erdinç Türkyılmaz, Umut Rona, who contributed to both the empirical phase of the study and assessment of video recordings, and Uludağ University Taekwondo Club president Mustafa Aslan.

\section{Conflict of interest}

The authors declare no potential conflicts of interest with respect to the research, authorship, and/or publication of this article.

\section{References}

1. Birrer RB, Levine R. Performance parameters in children and adolescent athletes. Sports Med. 1987; 4(3): 211-227. https://doi.org/10.2165/00007256-198704030-00005

2. Gonçalves C EB, Rama L ML, Figueiredo AB. Talent identification and specialization in sport: An overview of some unanswered questions. Int J Sports Physiol Perform. 2012; 7: 390-393. https://doi.org/10.1123/ijspp.7.4.390

3. Elferink-Gemser MT, Jordet G, Coelho-E-Silva MJ, Visscher C. The marvels of elite sports: how to get there? $\mathrm{Br} J$ Sports Med. 2011; 45: 683-684. https://doi.org/10.1136/bjsports-2011-090254

4. Ali A. Measuring soccer skill performance: a review. Scand J Med Sci Sports. 2011; 21: 170-183. https://doi.org/10.1111/j.1600-0838.2010.01256.x

5. Andersen SS, Houlihan B, Ronglan LT. Managing Elite Sport Systems: Research and Practice. New York: Routledge; 2015.

6. Lees A. Science and the major racket sports: a review. $J$ Sports Sci. 2003; 21(9): 707-732. https://doi.org/10.1080/0264041031000140275

7. Mann DT, Williams AM, Ward P, Janelle CM. Perceptual-Cognitive Expertise in Sport: A MetaAnalysis. J Sport Exerc Psychol. 2007; 29(4): 457-478. https://doi.org/10.1123/jsep.29.4.457

8. Roca A, Ford PR, McRobert AP, Williams AM. Identifying the processes underpinning anticipation and decision-making in a dynamic timeconstrained task. Cogn Process. 2011; 12: 301-310. https://doi.org/10.1007/s10339-011-0392-1

9. Raab M, Masters RS, Maxwell JP. Improving the how and what decisions of elite table tennis players. Hum Mov Sci. 2005; 24(3): 326-344. https://doi.org/10.1016/j.humov.2005.06.004

10.Huijgen BCH, Leemhuis S, Kok NM, Verburgh L, Oosterlaan J, Elferink-Gemser MT, et al. Cognitive Functions in Elite and Sub-Elite Youth Soccer Players Aged 13 to 17 Years. PLoSONE. 2015; 10(12): e0144580. https://doi.org/10.1371/journal.pone.0144580

11. Kida N, Oda S, Matsumura M. Intensive baseball practice improves the Go/Nogo reaction time, but not the simple reaction time. Brain Res Cogn Brain Res. 2005; 22: 257-264. https://doi.org/10.1016/j.cogbrainres.2004.09.003

12.Pearson DT, Naughton GA, Torode M. Predictability of physiological testing and the role of maturation in talent identification for adolescent team sports. $J$ Sci Med Sport. 2006; 9: 277-287. https://doi.org/10.1016/j.jsams.2006.05.020

13.Höner O, Votteler A, Schmid M, Schultz F, Roth K. Psychometric properties of the motor diagnostics in the German football talent identification and development programme. $J$ Sports Sci. 2015; 33(2):145-159. https://doi.org/10.1080/02640414.2014.928416

14.Vaeyens R, Güllich A, Warr CR, Philippaerts R. Talent identification and promotion programmes of Olympic athletes. $J$ Sports Sci. 2009; 27(13): 1367-1380. https://doi.org/10.1080/02640410903110974

15.Breitbach S, Tug S, Simon P. Conventional and Genetic Talent Identification in Sports: Will Recent Developments Trace Talent? Sports Med. 2014; 44: 1489-1503. https://doi.org/10.1007/s40279-014-0221-7

16.Williams AM, Reilly T. Talent identification and development in soccer. J Sports Sci. 2000; 18(9): 657-667. https://doi.org/10.1080/02640410050120041

17.Faber IR, Nijhuis-Van Der Sanden MWG, Elferink-Gemser 
MT, Oosterveld FGJ. The Dutch motor skills assessment as tool for talent development in table tennis: a reproducibility and validity study. J Sports Sci. 2015; 33(11): 1149-1158. https://doi.org/10.1080/02640414.2014.986503

18.Crespo M, Reid MM. Motivation in tennis. Br J Sports Med. 2007; 41: 769-772. https://doi.org/10.1136/bjsm.2007.036285

19. Voss MW, Kramer AF, Chandramallika B, Prakash RS, Roberts B. Are Expert Athletes 'Expert' in the Cognitive Laboratory? A Meta-Analytic Review of Cognition and Sport Expertise. Appl Cognit Psychol. 2010; 24: 812-826. https://doi.org/10.1002/acp.1588

20.Chu C-Y, Chen I-T, Chen L-C, Huang C-J, Hung T-M. Sources of psychological states related to peak performance in elite table tennis players. The 12th ITTF Sports Science Congress. 2011.P.200-210.

21.Reilly T, Williams AM, Nevill A, Franks A. A multidisciplinary approach to talent identification in soccer. $J$ Sports Sci. 2000; 18(9): 695-702. https://doi.org/10.1080/02640410050120078

22.Huijgen BC, Elferink-Gemser MT, Lemmink KA, Visscher C. Multidimensional performance characteristics in selected and deselected talented soccer players. Eur J Sport Sci. 2014; 14(1): 2-10. https://doi.org/10.1080/17461391.2012.725102

23.Vaeyens R, Lenoir M, Williams AM, Philippaerts RM. Talent Identification and Development Programmes in Sport: Current Models and Future Directions. Sports Med. 2008; 38(9): 703-714. https://doi.org/10.2165/00007256-200838090-00001

24.Faber IR, Bustin PMJ, Oosterveld FGJ, Elferink-Gemser MT, Nijhuis-Van Der Sanden MWG. Assessing personal talent determinants in young racquet sport players: a systematic review. J Sports Sci. 2016; 34(5): 395-410. https://doi.org/10.1080/02640414.2015.1061201

25.Faber IR, Oosterveld FGJ, Nijhuis-Van der Sanden MWG. Does an Eye-Hand Coordination Test Have Added Value as Part of Talent Identification in Table Tennis? A Validity and Reproducibility Study. PLoS ONE. 2014; 9(1): e85657. https://doi.org/10.1371/journal.pone.0085657

26.Sagdilek E, Sahin S. A new method highlighting psychomotor skills and cognitive attributes in athlete selections. Sport Mont. 2015; 43-45: 218-224.

27.Sahin SK, Sagdilek E. Could Computer Game Players React as Quick as Table Tennis Athletes and Perform the Right Action? Medical Science and Discovery. 2016; 3(2): 91-97.

28.Sahin S, Sagdilek E, Cimen O. Assesment of a new method highlighting cognitive attributes with table tennis athletes. Sport Mont. 2015; 43-45: 245-251.

29.Crabtree DA, Antrim LR. Guidelines for measuring reaction time. Percept Mot Skills. 1988, 66, 363-370. https://doi.org/10.2466/pms.1988.66.2.363

30.Niemi P, Näätänen R. Foreperiod and simple reaction time. Psychol Bull. 1981, 89(1), 133-162.

31.Rodrigues ST, Vickers JN, Williams AM. Head, Eye and Arm Coordination in Table Tennis. J Sports Sci. 2002; 20: 187-200. https://doi.org/10.1080/026404102317284754

32.Toriola AL, Toriola OM, Igbokwe NU. Validity of specific motor skills in predicting table-tennis performance in novice players. Percept Mot Skills. 2004; 98(2): 584-586. https://doi.org/10.2466/pms.98.2.584-586

33.Water T, Huijgen B, Faber I, ElferinkGemser M. Assessing Cognitive Performance in Badminton Players: A Reproducibility and Validity Study. J Hum Kinet. 2017; 55: 149-159. https://doi.org/10.1515/hukin-2017-0014

\section{Information about the authors:}

Sagdilek E.; (Corresponding author); http://orcid.org/0000-0001-8696-4035; esagdilek@hotmail.com; Faculty of Medicine, Department of Biophysics, Bursa Uludağ University; 16059, Bursa, Turkey.

Sahin S.K.; http://orcid.org/0000-0002-9221-0616; skoparan2013@gmail.com; Faculty of Sport Sciences, Department of Coach Training in Sports, Bursa Uludağ University; 16059, Bursa, Turkey.

Cite this article as:

Sagdilek E, Sahin SK. Instruction-based selective action pattern (IBSAP): a novel method for talent identification in sports. Pedagogics, psychology, medical-biological problems of physical training and sports, 2019;23(5):246-253. https://doi.org/10.15561/18189172.2019.0506

This is an Open Access article distributed under the terms of the Creative Commons Attribution License, which permits unrestricted use, distribution, and reproduction in any medium, provided the original work is properly cited (http://creativecommons.org/licenses/by/4.0/deed.en).

Received: 14.07.2019

Accepted: 12.08.2019; Published: 17.09.2019 